\section{Actualidades en el mundo de la neumología y la cirugía torácica}

\section{Contenido}

- Situación de la influenza en América

- Enfermedad por el virus del Ébola, implicaciones de la introducción en las Américas

- Noticias de interés

\section{SITUACIÓN DE LA INFLUENZA EN AMÉRICA}

La información presentada en esta actualización se obtiene a partir de los datos distribuidos por los Ministerios de Salud de los Estados Miembros y de los Centros Nacionales de Influenza de los Estados Miembros de la Organización Panamericana de la Salud (OPS) al 5 de diciembre de 2014.

Ante el inicio de la temporada de influenza estacional en el hemisferio norte, la OPS/Organización Mundial de la Salud (OMS) recomienda a los Estados Miembros que adopten las medidas necesarias para asegurar el manejo clínico apropiado, el estricto cumplimiento de las medidas de control de infecciones en los servicios de atención de salud y la provisión adecuada de antivirales. Se insta, además, a que continúen con las actividades de vacunación contra la influenza estacional para reducir hospitalizaciones y evitar defunciones.

América del Norte: En Canadá, en la semana epidemiológica (SE) 47 de 2014, a nivel nacional se incrementó la actividad de influenza comparado con lo registrado en semanas anteriores. Este incremento se viene registrando desde la SE 37. El virus predominante es influenza $\mathrm{A}(\mathrm{H} 3 \mathrm{~N} 2)$. Durante la temporada de influenza 20142015, el Laboratorio Nacional de Micro- biología (LNM) caracterizó 10 virus de influenza $\mathrm{A}(\mathrm{H} 3 \mathrm{~N} 2)$, de los cuales dos resultaron ser antigénicamente similares al virus de influenza $\mathrm{A}(\mathrm{H} 3 \mathrm{~N} 2) \mathrm{A} /$ Texas/50/2012 (componente de la vacuna para esta temporada) y ocho demostraron un título reducido al antisuero producido contra la cepa recomendada para la vacuna (/Texas/50/2012).

En Estados Unidos aunque la actividad de influenza a nivel nacional es baja, algunas áreas del sur del país comenzaron a registrar una moderada y alta actividad, se espera un mayor incremento en las próximas semanas. La proporción de consultas por enfermedad -tipo- influenza (ETI) durante la SE 48 de 2014 alcanzó el $2.6 \%$, por encima de la línea de base nacional (2\%). Hasta la SE 48 la mortalidad por neumonía e influenza se mantiene por debajo del umbral epidémico. El virus predominante es influenza $\mathrm{A}(\mathrm{H} 3 \mathrm{~N} 2)$.

Los CDC de Estados Unidos informaron en una alerta de salud emitida el 3 de diciembre de 2014 , que el $48 \%$ de los virus de influenza $\mathrm{A}(\mathrm{H} 3 \mathrm{~N} 2)$ colectados y analizados entre el 1 de octubre y 22 de noviembre de 2014 ( $n=85)$, fueron antigénicamente similares al virus de influenza $\mathrm{A}(\mathrm{H} 3 \mathrm{~N} 2)$ que compone la vacuna contra influenza 2014-2015 del hemisferio norte, A/Texas/50/2012. Esto significa que hay un $52 \%$ de diferencia (drift antigénico) entre el virus de influenza A(H3N2) circulante y el componente de la vacuna 2014-2015 para el hemisferio norte. Aún con esta diferencia, la vacuna ofrece cierta protección contra los virus con cambios antigénicos mínimos y contra los virus circulantes sin cambios antigénicos; por ende, ayuda a prevenir casos graves y defunciones asociadas a influenza.

México: La actividad de influenza se encuentra dentro del canal endémico, y la proporción de consultas por ETI e infección respiratoria aguda grave (IRAG) permanece debajo del $2 \%$.

\section{Recomendaciones}

Ante el inicio de la temporada de mayor circulación de influenza en el hemisferio norte, la OPS/OMS hace las siguientes recomendaciones a los Estados Miembros relacionadas al manejo clínico adecuado de pacientes, a la implementación de medidas de control de infecciones en los servicios de atención de salud y a la comunicación con la población sobre las medidas de prevención.

\section{Manejo clínico}

En todo paciente con cuadro febril y síntomas respiratorios que consulte en un servicio de salud, debe considerarse la posibilidad de que sea una infección por influenza.

Algunos grupos requieren atención especial por su mayor riesgo a las infecciones graves; entre ellos, los menores de dos años de edad, adultos mayores de 65 años, mujeres embarazadas y personas con afecciones clínicas subyacentes. En estos casos debe considerarse la administración de tratamiento antiviral (oseltamivir) al inicio de los síntomas.

El tratamiento debe iniciarse aun antes de tener la confirmación de infección por influenza por el laboratorio. El tratamiento resulta exitoso con mayor frecuencia si se inicia de manera temprana.

\section{Control de infecciones}

Se deben tomar las medidas apropiadas para la prevención y el control de las infecciones en cada ocasión (precauciones estándar y precauciones para gotitas). Cuando se realicen procedimientos que generen aerosoles (por ejemplo, broncoscopia o cualquier procedimiento que ocasione aspiración del tracto respiratorio), es necesario que el personal de salud utilice un respirador contra partículas (N95, FFP2 o equivalente), protección ocular, bata y guantes, y que el procedimiento se 
realice en una habitación que pueda ser ventilada de manera natural o mecánica, según las guías de OMS.

\section{Vacunación}

La OPS/OMS recomienda que las mujeres embarazadas tengan la más alta prioridad en recibir las vacunas contra la influenza, debido a su vulnerabilidad a enfrentar complicaciones por esta enfermedad. Otros grupos de riesgo que deben ser considerados prioritarios para la vacunación son los adultos mayores, los niños de 6 a 59 meses de edad (con especial énfasis en 6-23 meses), las personas con afecciones médicas crónicas específicas y los trabajadores de salud.

\section{SITUACIÓN DE LA INFLUENZA EN EL INER}

La gráfica muestra la situación de la influenza en el Instituto Nacional de Enfermedades Respiratorias Ismael Cosío Villegas, Ciudad de México, en el período del 23 de abril de 2009 al 4 de diciembre de 2014 (figura 1).

\section{ENFERMEDAD POR EL VIRUS DEL ÉBOLA, IMPLICACIONES DE LA INTRODUCCIÓN EN LAS AMÉRICAS}

Considerando la situación actual de la enfermedad por el virus del Ébola (EVE) en África Occidental, la OPS/OMS recomienda a los Estados Miembros permanecer vigilantes ante la potencial introducción del EVE en las Américas, concientizar y ampliar el conocimiento de la enfermedad en los trabajadores de la salud, y fortalecer la implementación de las medidas de prevención y control de infecciones, en todos los niveles de atención de los servicios de salud.

\section{La enfermedad por EVE}

LaEVE (anteriormente conocida como fiebre hemorrágica del Ébola) es una enfermedad grave, con una tasa de letalidad de hasta un 90\%. No existe un tratamiento específico aprobado, ni vacuna con licencia disponible para el uso en seres humanos o animales.

El género Ébola virus es 1 de los 3 grupos de la familia Filoviridae (filovirus) junto con los géneros Marburgvirus y Cuevavirus. El género Ébola virus comprende cinco especies distintas: Bundibugyo Ébolavirus (BDBV), Zaire Ébolavirus (EBOV), Reston Ébolavirus (RESTV), Sudan Ébolavirus (SUDV) y Bosque Tai Ébolavirus (TAFV). El período de incubación de la EVE varía de 2 a 21 días, con un promedio de 8 a 10 días. Tras la introducción del virus Ébola en la población humana a través de la transmisión humano-animal, la transmisión persona a persona mediante el contacto directo con fluidos y/o secreciones corporales de las personas infectadas se considera como el principal modo de transmisión. La transmisión también puede ocurrir a través de contacto indirecto con el medio ambiente y fómites contaminados con fluidos corporales (por ejemplo, agujas). No se ha documentado transmisión por aerosoles durante los brotes anteriores de EVE. No existe riesgo de transmisión durante el período de incubación.

Los síntomas más comunes que presentan las personas infectadas con el virus Ébola son: fiebre de inicio repentino, debilidad intensa, dolor muscular, dolor de cabeza y dolor de garganta, seguido por vómitos, diarrea, erup-

\section{SEGUIMIENTO DIARIO DE CASOS DE SOSPECHA DE INFLUENZA}

Actualizada al 04/12/2014

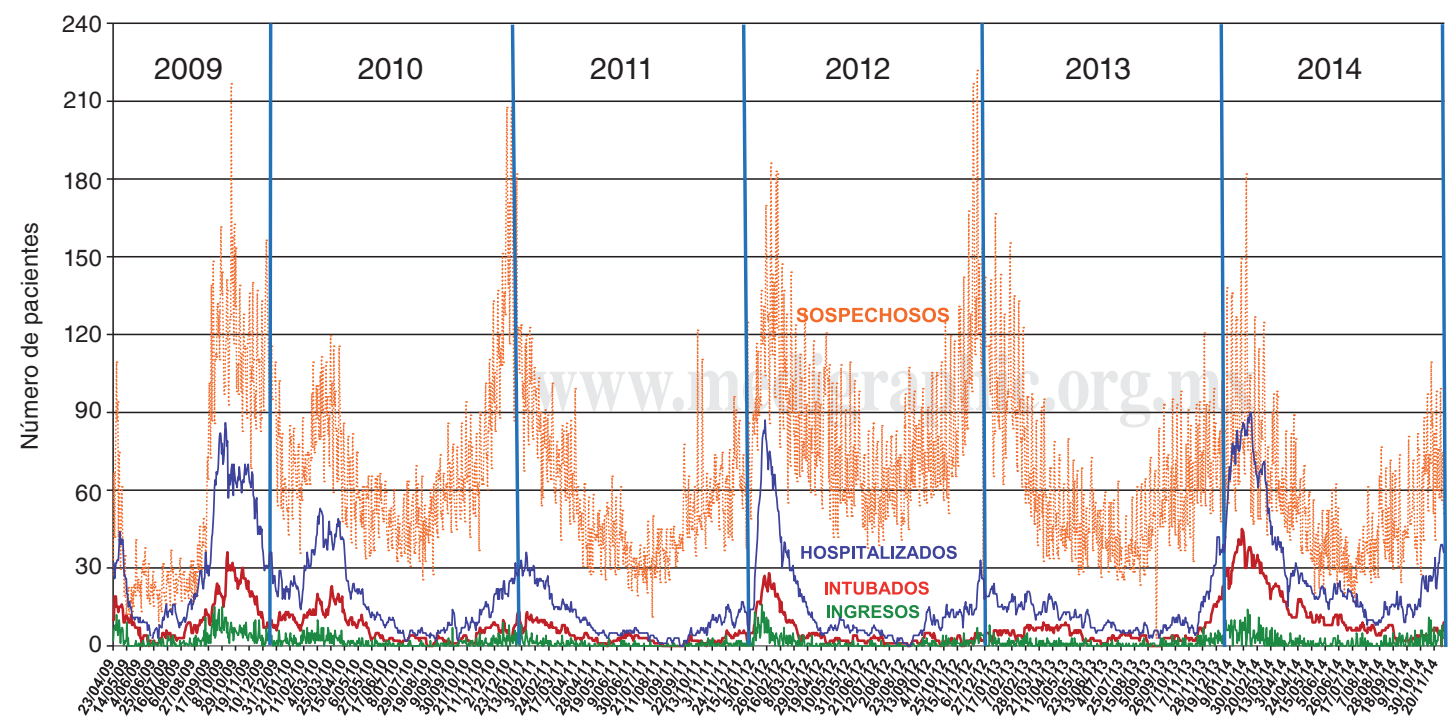

Figura 1. 
ción cutánea, deterioro de la función renal y hepática; y en una fase avanzada, hemorragias tanto internas como externas. Los hallazgos de laboratorio incluyen leucopenia, trombocitopenia y enzimas hepáticas elevadas.

Para mayor información: http://www. paho.org

\section{NOTICIAS DE INTERÉS}

Aumenta tuberculosis las muertes por VIH. (1 de diciembre de 2014, Reforma p. 17/Opinión por Adriana Alatorre)

Información en la que se detalla respecto a que «un $13 \%$ de las muertes de las personas con VIH se da por tuberculosis afirmó la directora del Centro Nacional de Prevención y Control del VIH/SIDA (Censida), Patricia Uribe. 'En México, $5.6 \%$ de los casos con tuberculosis tienen VIH. Por eso se debe recomendar que a toda persona con VIH se le haga la prueba de tuberculosis', dijo. La mayor parte de la tuberculosis vinculada a VIH es pulmonar, y el 91\% de los casos ocurrió en personas jóvenes. El 13 de noviembre de 2014 entraron en vigor los nuevos criterios de la OMS, que establecen que a toda persona se le debe dar la profilaxis para evitar la tuberculosis en cualquier momento. 'Es una prioridad. Lo tenemos claro, tenemos que disminuir este $13 \%$ como causa de mortalidad, lo tenemos puesto como una prioridad y como indicador, y se han hecho acuerdos firmados con todos los estados', indicó. Estimó que en el país viven 180 mil personas con VIH, de los cuales 10 mil son niños, de todas las edades, y la mitad podría no saberlo».

Prueba múltiple contra influenza. (1 de diciembre de 2014, Reforma p. 30/ Cultura)

Información en la que se detalla sobre que «una prueba de laboratorio capaz de identificar todas las variaciones del virus de la influenza ha sido desarrollada por científicos mexicanos de la UNAM. Este virus es nombrado por las proteínas debido a que existen 16 tipos de hemaglutinina $(\mathrm{H})$ y 9 tipos de neuraminidasa (N) en su superficie, las cuales suelen combinarse de diferente forma, dando origen a distintos tipos de influenza, como la H1N1, H5N1 o H7N9. En México, el Instituto de Diagnóstico y Referencia Epidemiológicos (InDRE) puede detec$\operatorname{tar} 4$ o 5 variantes del virus (influenza A [H1N1] pdm09, influenza H1N1 estacional, influenza H3N2 estacional, influenza B linajes Victoria y Yamagata), indica el Manual de Lineamientos de Vigilancia Epidemiológica de Influenza, de la Secretaría de Salud. Pero cuando se presenta una variante nueva, la muestra debe ser enviada a Estados Unidos o Canadá. Por ello, el doctor Carlos Arias Ortiz, del Instituto de Biotecnología de la UNAM, ha desarrollado una prueba capaz de revisar todas las variaciones en estas dos proteínas, la cual está en etapa piloto, pero que ha sido capaz de detectar, hasta el momento, ocho diferentes variedades».

Vacuna contra influenza reduce riesgo de accidentes cerebrovasculares. (27 de noviembre de 2014, La Jornada p. 49 por Ángeles Cruz Martínez)

«La aplicación de la vacuna contra la influenza en adultos mayores reduce el riesgo de eventos en el cerebro y cardiovasculares, y junto con la preventiva del neumococo disminuye 40 por ciento la cantidad de enfermos que requieren hospitalización, así como las muertes por estas enfermedades, afirmó Luis Miguel Gutiérrez, director del Instituto Nacional de Geriatría». Tras destacar lo anterior, se refiere que «en conferencia de prensa, el especialista informó sobre la reunión de la Academia de Medicina de Francia y la Academia Nacional de Medicina de México donde sus integrantes abordaron el tema Vacunación en el adulto mayor: perspectiva de curso de vida, e intercambiaron experiencias y conocimientos».

\section{$\triangle$ Correspondencia:}

Lic. Gustavo Giraldo-Buitrago, Jefe del Departamento de Relaciones Públicas y Comunicación Social, Instituto Nacional de Enfermedades Respiratorias Ismael Cosío Villegas. Calzada de Tlalpan Núm. 4502,

Colonia Sección XVI, México, D.F., 14080.

Correo electrónico: gustavo.giraldo@gmail.com 